\title{
Screening for breast cancer
}

\author{
W D GEORGE, E N GLEAVE, P C ENGLAND, M C WILSON, R A SELLWOOD, D ASBURY, \\ G HARTLEY, P G BARKER, P HOBBS, J WAKEFIELD
}

British Medical fournal, 1976, 2, 858-860

\section{Summary}

The feasibility of mass population screening for breast cancer by clinical examination and $x$-ray mammography was studied. The results indicate that such a programme could be conducted effectively by non-medical staff and be safe from the dangers of irradiation. The response rate of women invited for screening suggests that such a service is acceptable to the general public. The additional work load produced by screening would not overburden the existing surgical services.

\section{Introduction}

The results of a controlled clinical trial carried out by the Health Insurance Plan of Greater New York $^{1}$ suggest that screening for breast cancer leads to cancers being detected early and consequently to a significant reduction in mortality. This work aroused considerable interest in Britain, and the Department of Health and Social Security has been urged repeatedly to provide a screening programme within the National Health Service. In response it established three centres, in Edinburgh, Ealing, and South Manchester, to investigate the feasibility of establishing a nationwide service. In South Manchester our task was to answer the following questions: (1) Can screening be done by non-medical staff? With our present medical manpower resources this would be the only way of providing a regular service for all women at risk. (2) Is it safe ? There are possible dangers from radiation associated with repeated mammography. ${ }^{2-4}$ (3) Is screening acceptable to

Professorial Surgical Unit, University Hospital of South Manchester, Manchester M20 8LR

W D GEORGE, FRCs, lecturer in surgery

E N GLEAVE, FRCs, senior lecturer in surgery

$P$ C ENGLAND, MD, FRCs, lecturer in surgery

M C WILSON, FRCS, tutor in surgery

R A SELLWOOD, CHM, FRCS, professor of surgery

Department of Radiology, University Hospital of South Manchester, Manchester, M20 8LR

D ASBURY, MB, FFR, consultant radiologist

G HARTLEY, MB, FFR, consultant radiologis

Department of Social Research, University Hospital of South Manchester, Manchester M20 8LR

P HOBBS, MSC, principal research officer

$\mathrm{J}$ WAKEFIELD, PHD, director

Regional Department of Physics

P G BARKER, BSC women at risk? (4) How great is the additional surgical work load ? Screening detects many more benign lumps than malignant ones, and, apart from cysts, most require biopsy.

\section{Methods}

A special clinic was established in the University Hospital of South Manchester to screen women by clinical examination and mammography.

\section{POPULATION}

Invited women-Age and sex registers were drawn up for two large group practices in South Manchester and all women over the age of 50 invited to attend for screening. Those who failed to respond received a second invitation. The factors that influenced response were studied by personal interviews of random samples of attenders $(n=101)$ and non-attenders $(n=101)$.

Self-referred women-Many women attended for a screening examination without invitation or referral.

Referred women-All patients referred to the professorial surgical unit because of symptoms of breast disease were examined in the same clinic and in the same way as the invited women and self-referred women.

\section{TRAINING AND ASSESSMENT OF NON-MEDICAL STAFF}

Nurses and radiographers were recruited and given basic training in all aspects of breast disease. Additional practical instruction in clinical examination was given to nurses and in interpretation of mammograms to radiographers. After training was completed each patient who attended the clinic was examined independently by a nurse and a surgeon and each recorded his findings on separate standard documents. Similarly each mammogram was read and recorded separately by a radiographer and a consultant radiologist.

The performance of the nurses and radiographers was studied in those patients with histological proof of cancer. Assessment was based on their absolute diagnostic accuracy and on their ability to detect significant abnormalities that led to subsequent referral and biopsy. Thus we compared the performance of nurses and surgeions, of radiographers and radiologists, and of the joint medical and nonmedical teams.

\section{MAMMOGRAPHIC EXAMINATION}

Women invited for a screening examination and self-referred or referred patients over the age of 50 all underwent routine $x$-ray examination. In younger patients with symptoms mammography was carried out only if there was a clinical indication. The equipment used was a Watson Mammostand fitted with a rotating molybdenum target. Craniocaudad and lateral views were taken of each breast by one of four radiological methods: (a) standard industrial $x$-ray film (Kodak Industrex $\mathrm{C})$; (b) medichrome film with a Kodak intensifying screen; (c) medichrome film with an Ilford intensifying screen; $(d)$ the trimax film screen combination. 
The dose of direct and scattered radiation received by the skin of the breast during the whole examination was measured in all four quadrants by the lithium fluoride thermoluminescent method. ${ }^{5}$ For the craniocaudad views compression was applied to the breast with a perspex plate designed locally.

\section{SURGICAL WORK LOAD PRODUCED BY SCREENING}

To estimate the surgical work load we assumed that the negative biopsies performed on women who attended for screening in response to invitation represented additional work that would not otherwise have been carried out. This biopsy rate was extrapolated to a larger population.

\section{Results}

Of the 4671 women who attended the clinic between 1 January 1973 and 14 July 1975, 1671 attended in response to invitation, 1055 attended without invitation, and 1945 were referred because of symptoms or signs.

Invited women-Of the 1671 invited women, $48(2.9 \%)$ were found to have lesions that required biopsy, and in $16(1.0 \%)$ of these cancer of the breast was reported (table I). One hundred and eighty-two $\left(11^{\circ}{ }_{0}\right)$ of the invited women admitted to symptoms of some kind in relation to their breasts, and in these the incidence of cancer $(4.4 \%)$ was significantly greater than that in those who were free from symptoms $\left(0.5^{\circ}\right)$.

TABLE I-Incidence of benign and malignant lesions related to source of patients and symptoms

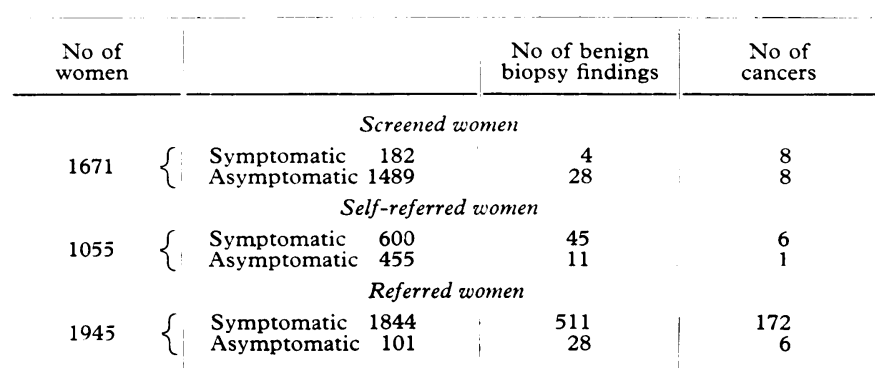

Self-referred women-Of the 1055 self-referred women $63\left(6^{\circ} \%\right)$ required a biopsy and seven $\left(0 \cdot 7^{\circ}\right.$ o $)$ were found to have cancer. Six hundred $\left(57^{\circ}\right)$ of these women admitted to symptoms of breast disease, and $\operatorname{six}(1 \%)$ of these were found to have cancer.

Referred women-Of the 1945 women referred by their general practitioners $717\left(37^{\circ}\right)$ required biopsy and $178\left(9.2^{\circ} \%\right)$ were found to have cancer.

The total experience available to the nine nurses and seven radiographers who worked in the clinic at some time was thus 828 significant lesions of the breast, of which 201 were cancers.

\section{PERFORMANCE OF TRAINEES}

In the 201 patients with cancer the diagnostic accuracy of the surgeons $(88 \%)$ was better than that of the nurses $(78 \%)$. The surgeons found a significant local abnormality in $98^{\circ}$ of the women and the nurses found one in $94 \%$. There was little difference in diagnostic accuracy between the radiologists and radiographers $(71 \%$ and $73 \%$ respectively) but the radiographers found a significant local abnormality in more of the patients $(82 \%)$ than did the radiologists $(77 \%)$. The joint medical team found a significant abnormality in all but two of the 201 cancers and the non-medical team in all but five (table II)

When the 16 cancers detected in women invited for screening were considered as a separate group (table III) a different pattern emerged. In these patients the nurses' ability to detect significant abnormalities $(63 \%)$ was less than that in the total series of cancers, but that of the radiographers $(81 \%$ ) remained unchanged. As a team they detected a significant abnormality in 14 of the 16 patients, but the contribution made by the radiographers was more important than in the total series.

In the total series only two $(1 \%)$ of the cancers detected by the medical team were found solely by mammography (table IV), but
TABLE II-Diagnostic accuracy and rate of recognition of significant abnormalities in 201 cancers examined clinically and radiologically

\begin{tabular}{l|cc|c} 
& $\begin{array}{c}\text { No (",) of } \\
\text { accurate } \\
\text { diagnoses }\end{array}$ & $\begin{array}{c}\text { No ( }{ }^{\circ} \% \text { of } \\
\text { significant } \\
\text { abnormalities } \\
\text { detected }\end{array}$ & $\begin{array}{c}\text { No of } \\
\text { cancers missed }\end{array}$ \\
\hline Surgeons & $176(88)$ & $197(98)$ & 4 \\
Nurses & $156(78)$ & $188(94)$ & 13 \\
Radiologists & $143(71)$ & $154(77)$ & 47 \\
Radiographers & $146(73)$ & $164(82)$ & 37 \\
Medical team & $183(91)$ & $199(99)$ & 2 \\
Non-medical team & $172(86)$ & $196(98)$ & 5
\end{tabular}

TABLE III-Diagnostic accuracy and rate of recognition of significant abnormalities in 16 patients with cancer among women invited to attend for a screening examination

\begin{tabular}{l|cc|c} 
& $\begin{array}{c}\text { No (\%) of } \\
\text { accurate } \\
\text { diagnoses }\end{array}$ & $\begin{array}{c}\text { No (\%) of } \\
\text { significant } \\
\text { abnormalities } \\
\text { detected }\end{array}$ & $\begin{array}{c}\text { No of } \\
\text { cancers missed }\end{array}$ \\
\hline Surgeons & $13(81)$ & $14(88)$ & 2 \\
Nurses & $7(44)$ & $10(63)$ & 6 \\
Radiologists & $13(81)$ & $13(81)$ & 3 \\
Radiographers & $13(81)$ & $13(81)$ & 3 \\
Medical team & $13(100)$ & $16(100)$ & 0 \\
Non medical team & $13(81)$ & $14(88)$ & 2 \\
\hline
\end{tabular}

TABLE IV-Methods of detection in the total series of 201 cancers and in the 16 cancers found in women invited for screening

\begin{tabular}{|c|c|c|c|c|}
\hline \multirow[b]{2}{*}{ Detected } & \multicolumn{2}{|c|}{ Total series (201 cancers) } & \multicolumn{2}{|c|}{16 cancers in invited women } \\
\hline & Medical team & $\begin{array}{c}\text { Non-medical } \\
\text { team }\end{array}$ & Medical team & $\begin{array}{c}\text { Non-medical } \\
\text { team }\end{array}$ \\
\hline $\begin{array}{l}\text { Clinically } \\
\text { Radiologically } \\
\text { Both methods }\end{array}$ & $\begin{array}{c}45\left(22^{\prime \prime}{ }^{\prime \prime 1}\right) \\
2\left(1{ }^{\prime \prime}\right) \\
152\left(76^{\circ}{ }_{10}\right)\end{array}$ & $\begin{array}{c}32\left(16_{0}^{\circ}\right) \\
8(4 \%) \\
156(78 \%)\end{array}$ & $\begin{array}{r}3(19 \%) \\
2(13 \%) \\
11(69 \%)\end{array}$ & $\begin{array}{l}1(6 \%) \\
4\left(25^{\circ}\right) \\
9\left(56_{0}^{\circ}\right)\end{array}$ \\
\hline Total & $199\left(99^{\prime \prime}{ }_{11}\right)$ & $196\left(98^{\circ}{ }_{6}\right)$ & $16\left(100_{\%}^{\circ}\right)$ & $14\left(88^{\circ}\right)$ \\
\hline
\end{tabular}

both were in women invited for screening. Radiology was of greater value to the non-medical team. It was solely responsible for the detection of eight cancers $(4 \%)$ in the total series, four of which were in women invited for screening. Clinical examination was responsible for detecting $45(23 \%)$ of the cancers found by the medical team and $32(16 \%)$ of those found by the non-medical team. Only one of the cancers found by the non-medical team in the invited women was detected solely by clinical examination.

\section{RADIATION DOSE}

Standard industrial x-ray film (Kodak Industrex $C$ ) - In 22 patients studied initially the dose was invariably highest in the upper inner quadrant with a mean $( \pm S D)$ of $7 \cdot 1 \pm 3 \cdot 7$ rads. The next highest was the lower inner quadrant with a mean of 5.5 rads. The two outer quadrants received lower doses. When measurements were made in a further 24 patients after the radiographers had gained more experience the dose to the upper inner quadrant was reduced to $4 \cdot 9 \pm 1 \cdot 18$ rads.

Medichrome blue film and Kodak high resolution back screen-In 25 patients the mean dose to the upper inner quadrant $(1 \cdot 1 \pm 0.29$ rads $)$ was reduced significantly $(P<0.001)$ when compared with the dose required for industrial film.

Medichrome blue film and Ilford high definition back screen-In 18 patients the mean dose to the upper inner quadrant $(0.5 \pm 0.2$ rads $)$ was reduced significantly $(P<0.001)$ when compared with the dose required for either the same film used with a Kodak screen or the industrial film.

Trimax XD film and rare earth phosphor screen-In 24 patients the mean dose to the upper inner quadrant $(0 \cdot 18 \pm 0 \cdot 05$ rads $)$ was reduced significantly $(\mathrm{P}<0.001)$ when compared with the doses required for the other film and film screen combinations.

\section{RESPONSE OF POPULATION}

The overall response rate to the invitation to be screened was $54 \%$ In women aged 50-59 it was $63 \%$, in those aged $60-69$ it was $55 \%$, and in those aged over 70 it was $34 \%$ 
Attendance in response to invitation was not influenced by social class. Of the women invited for screening, $38 \%$ were in the upper social groups (social classes I, II, and III non-manual); $34 \%$ were in the lower groups (social classes III manual, IV, and V); and $28^{\circ}$ o were housewives. Of those who attended, $42 \%$ were in the upper social groups $; 34 \%$ were in the lower groups; and $24 \%$ were housewives.

Women with a history of breast disease were more likely to attend than those without. Of those who responded to invitation, $86 \%$ were hopeful about the treatment of cancer compared with $63 \%$ of those who failed to respond. Only one of those who came for screening was uncertain about the advantages of early treatment for cancer, whereas $18 \%$ of the non-attenders thought that it made no difference or did not know.

Attendance by self-referral was influenced by social class. Of the women who referred themselves for screening, $55^{\circ}$ owere in the upper social groups, $19^{\circ}$ o were in the lower groups, and $26^{\circ}{ }_{\circ}$ were housewives.

\section{SURGICAL WORK LOAD}

Thirty-two biopsies of benign tissue were performed on the 1671 invited women, a biopsy rate of $1 \cdot 9^{\circ}$. These data were extrapolated to the 85000 women in Manchester aged 40-65 years. We estimated that 51300 women would attend for screening, and 975 would need biopsies. This would represent 20 additional biopsies each week, or five for each of the four major hospitals in the city.

\section{Discussion}

Clearly when acting together as a team nurses and radiographers can detect significant abnormalities as effectively as medical staff. These findings suggest that non-medical staff could act effectively as primary screeners if adequate facilities for subsequent referral and treatment were available. The nurses were less effective in detecting cancers among women invited for screening than they were in detecting cancers in the whole series. This was because they failed to detect any significant abnormality in six of the eight cancers found in asymptomatic invited women. Nurses seem to be much less effective when there are no symptoms to suggest an abnormality. This underlines the value of radiology, which was more effective than clinical examination in detecting cancer in asymptomatic screened women. If the 23 cancers found in invited and selfreferred women are considered as cancers detected by "screening," $21(91 \%)$ were found by the non-medical team: 14 were found by both methods of examination, two by clinical examination only, and five by mammography. A screening service run by non-medical staff should include both clinical examination and mammography.

The rate of cancer detection in "screened" women (invited and self-referred) seems high (8.4 per 1000), but many of the women with cancer knew that an abnormality was present, and in asymptomatic women the detection rate was 4.6 per 1000 .

Radiation can cause cancer of the breast. ${ }^{2-4}$ In the context of a six-monthly mammographic examination over 10 years Ellis ${ }^{4}$ concluded that "unless the dose level per examination was reduced to at most 2 rads then the risk of breast cancer induction might have to be taken into account in population screening examinations." Our initial results indicate that doses below 2 rads per total examination cannot be achieved with traditional industrial miality film, which should not be used for screening. Any of the film screen combinations described would provide a suitable alternative, but the Trimax system produced the lowest dose of all. Low dose systems result in some loss of fine detail, and the best compromise between dose of radiation and high quality films is presently being investigated.

In our study $54 \%$ of the women invited attended for an examination. This is similar to the response rate of women who have never before been invited to take part in schemes of this kind. ${ }^{6}$ It compares with a $65 \%$ response rate in New York, ${ }^{1}$ but in both studies response was related inversely to age, and the higher response rate in New York was almost certainly due to the younger population studied. If screening is offered to younger populations than the one in this study the response rate will probably be higher. Women from the upper social groups use screening facilities whether or not they are invited to do so, often as an alternative to consulting their own doctor. To ensure that women from the middle and lower social groupings attend for screening a personal invitation is required.

It is not possible to define accurately the additional surgical work which results from screening. The biopsy rate for invited women was $1.9 \%$, but this might apply only to the first year of a screening service and would probably decrease in subsequent years. It will depend on the age of the population screened.

It seems therefore that non-medical staff can operate a safe effective screening service which would not overburden existing surgical services and which would be acceptable to most women at risk.

We thank the Department of Health and Social Security for their generous grant, which has made this work possible, and for their helpful advice and support throughout the project. We are grateful to the staff of the regional computer centre for their help; Dr Blumfield, Dr McShane, and their colleagues in general practice; the nurses, radiographers, and secretaries in the breast clinic; and Miss Ann Meakin for secretarial help.

\section{References}

${ }^{1}$ Shapiro, S, et al, Proceedings of the National Cancer Conference, 1973, 7, 663.

2 Wanebo, C K, et al, New England Fournal of Medicine, 1968, 279, 667.

${ }^{3}$ MacKenzie, I, British Fournal of Cancer, 1965, 19, 1.

${ }^{4}$ Ellis, R E, British fournal of Radiology, 1972, 45, 795.

5 Holm, N W, and Berry, R J, Manual on Radiation Dosimetry. Marcel Dekker Inc, 1970.

${ }^{6}$ Department of Health and Social Security, Seek Wisely to Prevent, ed J Wakefield, London, HMSO, 1972.

At what age should a girl of 7 whose mother took regularly a daily dose of diethylstilboestrol during the first four months of pregnancy (not in Britain) be screened for an eventual vaginal malignant transformation? What type of examination or tests should she be subjected to, if any?

This is a difficult question. Over-investigation should be avoided, yet the results of not diagnosing adenocarcinoma of the vagina in a young woman are serious. One estimate from the USA, where most cases have been found, is that there may be between 10000 and 16000 girls who were born between 1960 and $1970^{1}$ at risk. Yet few clinical cases of vaginal malignancy have been reported perhaps between 100 and 200 in women under $25 .^{2}$ Nevertheless, the anxiety generated by publicity in the mother and ultimately the daughter must be a factor in determining when to investigate and how much to do. Certainly any abnormal bleeding or discharge demands full gynaecological investigation, and irregular "menstruation" is potentially serious in such girls. The safest course, despite its obvious drawbacks, is to start investigations now, though a case could be made for delay until there are signs of puberty, since that is when many of the malignant lesions have presented. Alternatively, one could wait until the age of 9 or 10 . The difficulty is compounded by the need to repeat the investigations annually. Examination under anaesthesia is needed, with smears, biopsy of any abnormal area of the vagina or cervix, possibly random biopsy of the vagina for adenosis, colposcopy when this is available, and the noting of any vaginal hood or stricture, which also seems to be associated with diethylstilboestrol treatment during pregnancy. A brave doctor might decide that the risks of developing adenocarcinoma are so slight that investigation should wait until there are definite symptoms. Possibly the results of the treatment-total hysterectomy, bilateral salpingo-oophorectomy, total vaginectomy, and replacement of the vagina with a skin graftmay not be affected by whether the lesion is discovered very early or not too late. Prevention may not always be better than cure, and there may be the temptation to perform major prophylactic surgery when it might be unnecessary. This is always a risk whenever screening tests of any kind are done.

1 Heinonen, O P, Cancer, 1973, 31, 573.
2 Herbst, A L, Contemporary Obstetrics and Gynecology, 1973, 1, 19. 